\title{
Characterization of polydactyly-derived chondrocyte sheets versus adult chondrocyte sheets for articular cartilage repair
}

\author{
Miki Maehara ${ }^{1}$, Masato Sato ${ }^{{ }^{*}}$ (DD , Eriko Toyoda ${ }^{1}$, Takumi Takahashi ${ }^{1}$, Eri Okada', Tomomi Kotoku ${ }^{2}$
} and Masahiko Watanabe ${ }^{1}$

\begin{abstract}
Background: We previously conducted a first-in-human clinical study of articular cartilage repair using autologous chondrocyte sheets and confirmed the regeneration of hyaline-like cartilage in all eight patients. However, regenerative medicine with autologous chondrocyte sheets requires the harvesting of tissue from healthy regions, and the quality of this tissue varies between individuals. To overcome such limitations, allogeneic transplantation is a promising treatment method, particularly for articular cartilage repair. In this study, we investigated the characteristics of polydactyly-derived chondrocyte sheets fabricated from the chondrocytes of young polydactyly donors.
\end{abstract}

Methods: Polydactyly-derived chondrocyte (PD) sheets were fabricated from the tissue obtained from eight polydactyly donors (average age $=13.4$ months). To create these PD sheets, chondrocytes at passage 2 or 3 were seeded on temperature-responsive culture inserts and cultured for 2 weeks. For comparison, adult chondrocyte sheets were fabricated from tissue obtained from 11 patients who underwent total knee arthroplasty (TKA; average age $=74$ years). To create these TKA sheets, chondrocytes and synovial cells were cocultured, and the chondrocyte sheets were triple-layered according to the protocol from our previous clinical study. Cell count, cell viability, cell surface markers, cell histology, and humoral factors secreted by the sheets were characterized and compared between the PD sheets and TKA sheets.

Results: Polydactyly-derived chondrocytes proliferated rapidly to establish a layered structure with sufficient extracellular matrix and formed sheets that could be easily manipulated without tearing. Similar to TKA sheets, PD sheets expressed aggrecan and fibronectin at the protein level and the surface markers CD44, CD81, and CD90, which are characteristic of mesenchymal cells. PD sheets also produced significantly higher levels of transforming growth factor beta-1 and lower levels of matrix metalloproteinase-3 than those produced by TKA sheets, suggesting that young polydactyly-derived chondrocytes have advantages as a potential cell source.

Conclusions: PD sheets exhibited characteristics thought to be important to chondrocyte sheets as well as proliferative capacity that may facilitate provision of a stable supply in the future.

Keywords: Cartilage regeneration, Cell sheet technology, Chondrocyte sheet, Osteoarthritis, Polydactyly-derived chondrocyte

\footnotetext{
* Correspondence: sato-m@is.icc.u-tokai.ac.jp

${ }^{1}$ Department of Orthopaedic Surgery, Surgical Science, Tokai University

School of Medicine, Kanagawa, Japan

Full list of author information is available at the end of the article
} 


\section{Background}

Articular cartilage is composed mainly of hyaline cartilage, which exhibits viscoelastic properties. Because of its low cellularity and avascular nature, its capacity to selfregenerate after injury or degeneration is limited [1]. Existing treatment methods such as subchondral drilling $[2]$, microfracture $[3,4]$, and mosaicplasty $[5,6]$ are all symptomatic therapies that typically fill defects with inferior fibrocartilage, which lacks the mechanical properties exhibited by native hyaline cartilage. Since being first reported by Brittberg et al. [7] in 1994, autologous chondrocyte implantation (ACI) has been performed widely as an attempt to regenerate articular cartilage. However, regeneration with fibrocartilage or with a mixture of fibrocartilage and hyaline cartilage has been reported [8], and the advantage of ACI over existing methods is controversial [9]. As such, regeneration of hyaline cartilage is a challenge for regenerative medicine and is considered important in providing a long-term treatment.

In regenerative medicine, cell sheet technology $[10,11]$ has been applied to the regeneration of various tissues including the cornea [12], esophagus [13], myocardium [14], and periodontal tissue [15]. Culture dishes coated with temperature-responsive polymers $[16,17]$ allow the collection of cells as cell sheets without the use of digestive enzymes. The collection of cells with the extracellular matrix, cell-to-cell connections, and surface proteins intact makes this technology suited to regenerative medicine.

We have applied this technology to articular cartilage repair by developing chondrocyte sheets (i.e., sheets derived from chondrocytes) for the treatment of cartilage defects. We previously reported that culturing chondrocytes on temperature-responsive culture inserts and layering three sheets formed a strong three-dimensional structure [18]. We subsequently investigated the effectiveness of such layered chondrocyte sheets for the repair of full-thickness defects in rats [19], rabbits [20], and minipigs [21] and for the repair of partial-thickness defects in rabbits [22]. Having produced such evidence, we conducted a clinical study with autologous chondrocyte sheets and treated eight patients with cartilage defects accompanied by osteoarthritis. No adverse events were detected, and improvements in both clinical scores and regeneration of hyaline cartilage were confirmed in all patients (manuscript in preparation).

However, the fabrication and transplantation of autologous chondrocyte sheets require two surgeries, and the proliferative capacity of chondrocytes also varies greatly between individuals. To overcome these issues, we investigated the possibility of using allogeneic cell sources. Allogeneic transplantation of chondrocytes is known to be immunologically tolerated, and particulated juvenile cartilage implants (De Novo $\mathrm{NT}^{\odot}$; Zimmer, Warsaw, IN, USA) are used clinically in the USA [23]. To ensure traceability, we focused on the surgical remains obtained from polydactyly patients at Tokai University Hospital as a source of allogeneic chondrocytes.

In this study, we collected chondrocytes from polydactyly donors and fabricated polydactyly-derived chondrocyte (PD) sheets on temperature-responsive culture inserts. For comparison, adult chondrocyte sheets were fabricated from tissue obtained from patients who underwent total knee arthroplasty (TKA), hereafter called TKA sheets. To investigate the potential of using PDs as a cell source clinically, we compared the properties of PD sheets with those of TKA sheets.

\section{Methods}

All experiments were conducted with the approval of the Tokai University Ethics Committee and with either informed consent from the patient or parental permission.

\section{Fabrication of PD sheets}

Cartilage tissue was obtained from eight patients (average age 13.4 months, range $8-17$ months, four boys and four girls) who underwent polydactyly surgery at Tokai University Hospital. A summary of the PD sheet fabrication process is shown in Fig. 1a. Cartilage tissue was minced with scissors and subsequently incubated in Dulbecco's modified Eagle's medium/F12 (DMEM/F12; Gibco, Grand Island, NY, USA) supplemented with 20\% fetal bovine serum (FBS; AusGeneX, Molendinar, Australia), 1\% antibiotic-antimycotic solution (AB; Gibco), and $5 \mathrm{mg} / \mathrm{mL}$ collagenase type 1 (CLS1; Worthington, Mannheim, Germany) for $1.5 \mathrm{~h}$ at $37^{\circ} \mathrm{C}$ in a humidified atmosphere of $5 \% \mathrm{CO}_{2}$ and $95 \%$ air. The cell suspension was washed and passed through a $100-\mu \mathrm{m}$ strainer (BD Falcon, Franklin Lakes, NJ, USA).

The collected cells were seeded at a density of $1 \times 10^{4}$ cells $/ \mathrm{cm}^{2}$ on six-well culture plates (Corning, Corning, NY, USA) in DMEM/F12 supplemented with 20\% FBS and $1 \%$ $\mathrm{AB}$ and incubated at $37{ }^{\circ} \mathrm{C}$. After 4 days, $100 \mu \mathrm{g} / \mathrm{mL}$ ascorbic acid (Nissin Pharmaceutical, Yamagata, Japan) was added to the medium and the medium was replaced every 3 or 4 days. Cells were passaged once or twice when they reached confluence and then cryopreserved. To fabricate PD sheets, cells were thawed and passaged once and then seeded on temperature-responsive culture inserts (CellSeed Inc., Tokyo, Japan) at $1 \times 10^{4}$ cells $/ \mathrm{cm}^{2}$. After 2 weeks, the culture plates were kept at $25^{\circ} \mathrm{C}$ for $30 \mathrm{~min}$ to promote detachment of PD sheets from the inserts and the sheets were collected onto a polyvinylidene difluoride (PVDF) membrane. PD sheets were manipulated and visually confirmed to check for strength and any tearing. 


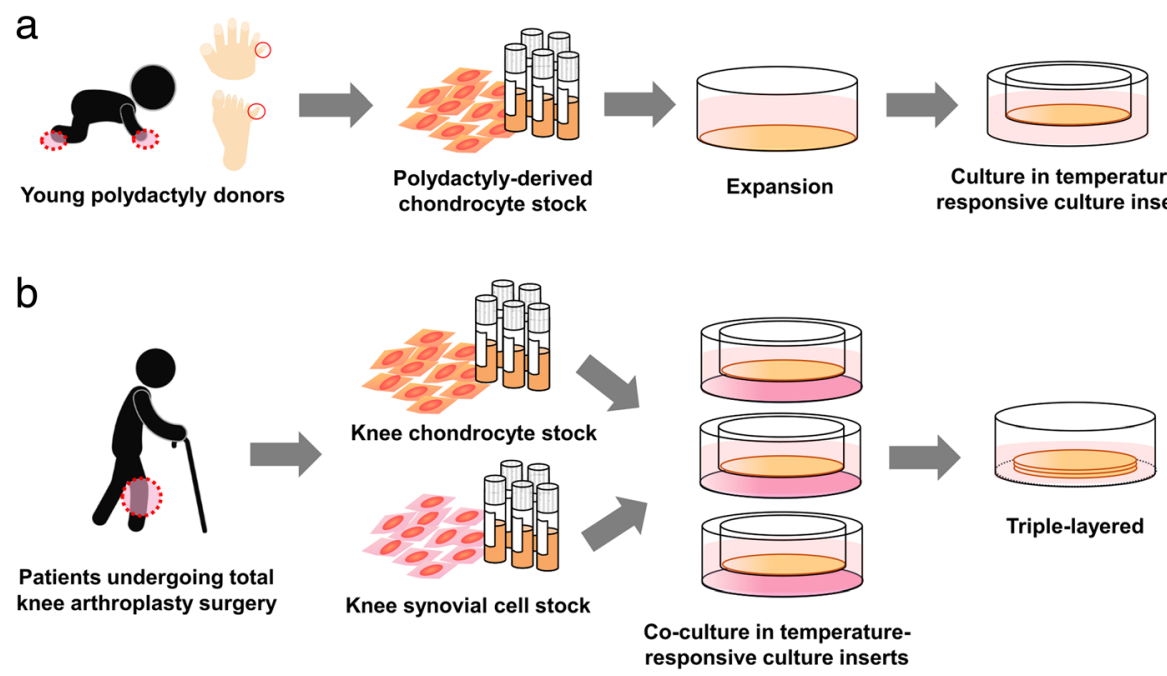

Fig. 1 Protocol for the fabrication of PD sheets and TKA sheets. a Fabrication of PD sheets. PDs obtained from polydactyly surgery were passaged once or twice and stocked at $-180^{\circ} \mathrm{C}$. After further expansion, $\mathrm{P} 2$ or P3 cells were seeded on temperature-responsive culture inserts and cultured for 2 weeks. b Fabrication of TKA sheets. Adult chondrocytes and synovial cells obtained from TKA surgery were stocked at P0 and P1, respectively. Chondrocytes were seeded on temperature-responsive culture inserts and cocultured with synovial cells for 2 weeks. Three chondrocyte sheets were layered and cultured for an additional week

\section{Fabrication of adult chondrocyte sheets}

Adult knee articular cartilage and synovium were obtained from 11 patients (average age 74 years, range 6779 years, five men and six women) who underwent TKA surgery at Tokai University Hospital. TKA sheets were fabricated according to previously reported methods $[24,25]$, which are similar to those used to create autologous chondrocyte sheets in our clinical study. A summary of the TKA sheet fabrication process is shown in Fig. 1b.

Briefly, cartilage and synovium were minced and subsequently incubated in DMEM/F12 supplemented with $20 \% \mathrm{FBS}, 1 \% \mathrm{AB}$, and $5 \mathrm{mg} / \mathrm{mL}$ CLS1 for 4 and $2 \mathrm{~h}$, respectively, at $37{ }^{\circ} \mathrm{C}$ in a humidified atmosphere of $5 \%$ $\mathrm{CO}_{2}$ and $95 \%$ air. The cell suspensions were washed and passed through $100-\mu \mathrm{m}$ strainers. Chondrocytes were cryopreserved, and synovial cells were seeded at $1 \times 10^{4}$ cells $/ \mathrm{cm}^{2}$ and cryopreserved after confluence. To fabricate TKA sheets, chondrocytes were seeded on temperatureresponsive culture inserts and cocultured with synovial cells for 2 weeks and three chondrocyte sheets were layered onto a PVDF membrane and cultured further for 1 week. TKA sheets were then manipulated and visually confirmed to check for strength and any tearing.

\section{Cell count and viability}

PD sheets and TKA sheets were washed in Dulbecco's phosphate-buffered saline (DPBS; Gibco). The sheets were then incubated in TripLE Express ${ }^{\circ}$ (Gibco) at $37^{\circ} \mathrm{C}$ for $15 \mathrm{~min}$ and centrifuged at $1500 \mathrm{rpm}$ for $5 \mathrm{~min}$. The cell sheets were resuspended in $0.25 \mathrm{mg} / \mathrm{mL}$ Collagenase
P (Roche, Basel, Switzerland) at $37{ }^{\circ} \mathrm{C}$ for up to $30 \mathrm{~min}$ and then centrifuged at $1500 \mathrm{rpm}$ for $5 \mathrm{~min}$. The isolated cells were finally resuspended in DMEM/F12, and cell count and viability were determined using the trypan blue exclusion assay.

\section{Flow cytometric analysis}

After obtaining the cell count, isolated cells were washed with DPBS containing $0.2 \%$ bovine serum albumin (BSA; Sigma-Aldrich, St. Louis, MO, USA) and $1 \mathrm{mM}$ ethylenediaminetetraacetic acid (EDTA; Gibco). About $1.5 \times 10^{5}$ cells were mixed in each tube with the following antibodies: hCD31-fluorescein isothiocyanate (FITC) (clone: 5.6E, Beckman \& Coulter, Brea, CA, USA), hCD44-FITC (clone: G44-26), hCD45-FITC (clone: J.33, Beckman \& Coulter), hCD81-allophycocyanin (APC) (clone: JS-81, BD Bioscience, Franklin, NJ, USA), and hCD90-APC (clone: 5E10, BD Bioscience). The cells were incubated for $90 \mathrm{~min}$ at $4{ }^{\circ} \mathrm{C}$ and then washed with DPBS containing $0.2 \%$ BSA and $1 \mathrm{mM}$ EDTA. Fluoroprobe-labeled mouse IgG1 antibody (clone: 679.1Mc7, Beckman \& Coulter) and mouse IgG2b antibody (clone: MG2b-57, Beckman \& Coulter) were used as negative controls. Stained cells were analyzed using a FACSVerse ${ }^{\mathrm{TM}}$ cell sorter (BD Bioscience).

\section{Histological and immunohistochemical staining}

PD sheets and TKA sheets were harvested after culture and then embedded and frozen in optimal cutting temperature compound (Sakura Finetek Japan, Tokyo, Japan). Then, sections $10 \mu \mathrm{m}$ thick were stained for 
proteoglycans with Safranin O or toluidine blue using standard methods. Sections $20 \mu \mathrm{m}$ thick were immunostained with anti-human type I collagen (COL1; 1:200; Southern Biotech, Birmingham, AL, USA), type II collagen (COL2; 1:200; Kyowa Pharma Chemical, Toyama, Japan), fibronectin (FN; 1:500; Merck, Darmstadt, Germany), and aggrecan (ACAN; 1:10; R\&D Systems, Minneapolis, MN, USA) at $4{ }^{\circ} \mathrm{C}$ overnight. The sections were washed and incubated at room temperature for $1 \mathrm{~h}$ with the secondary antibody Alexa Fluor 488-conjugated goat anti-mouse Ig (Thermo Fisher Scientific, MA, USA) for COL2 and FN or Alexa Fluor 546-conjugated donkey anti-goat Ig (Thermo Fisher Scientific) for COL1 and ACAN. After immunostaining, the sections were washed and mounted with VECTASHIELD Antifade Mounting Medium with 4',6-diamidino-2-phenylindole (Vector Laboratories, Burlingame, CA, USA). Microscopic images were captured under a BZ-8000 microscope (Keyence, Osaka, Japan).

\section{Measurement of humoral factors}

A random selection of fabricated PD sheets and TKA sheets were cultured for $72 \mathrm{~h}$ in $3 \mathrm{~mL}$ of DMEM/F12 supplemented with 1\% FBS and 1\% AB. Supernatants were collected and centrifuged at 15,000 $g$ for $10 \mathrm{~min}$ to remove cell debris. The concentrations of transforming growth factor beta-1 (TGF- $\beta 1 ; R \& D$ Systems), melanoma inhibitory activity (MIA; Roche), tissue inhibitor of metalloproteinases (TIMP1; R\&D Systems), matrix metalloproteinase-3 (MMP3; Sigma-Aldrich), stanniocalcin-1 (STC1; Cusabio, College Park, MD, USA), and hyaluronan and proteoglycan link protein 1 (HAPLN1; US Biological, Salem, MA, USA) were measured using enzyme-linked immunosorbent assay (ELISA) kits. The signal detected for blank medium containing 1\% FBS was subtracted to adjust for proteins contained in FBS. Measurements were repeated at least twice for each donor, and averages were used.

\section{Statistical analysis}

Numerical results are expressed as mean and standard deviation. Statistical analysis was performed using SPSS 23.0 software (IBM Corp., Armonk, NY, USA). Differences between the two groups were identified using Student's $t$ test. The level of significance was set at $P<0.05$.

\section{Results}

\section{Isolation and proliferation of PDs}

The average wet weight of cartilage tissue obtained from polydactyly donors was $0.3 \mathrm{~g}$, and the average number of cells collected after enzymatic digestion was $0.17 \times 10^{6}$ cells (Table 1). Cultured cells proliferated rapidly and reached confluence around day 5 (Fig. 2b), and cells grew to an average density of $3.7 \times 10^{6}$ cells or 22 times. Passage 1 (P1) or passage 2 (P2) cells were collected and stocked at $-180{ }^{\circ} \mathrm{C}$. After further expansion, P1 cells proliferated 7.8 times and P2 cells proliferated 4.8 times. From the polydactyly tissue obtained from one donor, we calculated that, theoretically, 693 P2 sheets and 3326 P3 sheets can be fabricated (Table 1). The average wet weight of cartilage tissue obtained from TKA donors was $9.2 \mathrm{~g}$, and the number of cells collected after enzymatic digestion was $18.5 \times 10^{6}$ cells. However, theoretically, only 29 layered TKA sheets can be created from the P0 cells (Table 1). Furthermore, only 1 to $3 \mathrm{~g}$ of cartilage tissue was collected during the clinical trial; therefore, the number of autologous chondrocyte sheets that were fabricated in the clinical trial was three to seven sheets.

Cell count, sheet thickness, and macroscopic observations Regardless of the type of donor, all PD sheets were a high density of cells through the 2 weeks of culture and without layering (Fig. 2d). PD sheets and TKA sheets were easily harvested and manipulated without tearing (Fig. 3a, b). An average PD sheet contained $2.6 \pm 0.8 \times 10^{6}$ cells with an average thickness of $15.2 \pm 4.0 \mu \mathrm{m}$. After a total of 3 weeks of culture, TKA sheets formed a thick structure with integrated layers (Fig. 3h). An average TKA sheet contained $1.6 \pm 0.1 \times 10^{6}$ cells with an average thickness of $45.5 \pm 14.6 \mu \mathrm{m}$.

\section{Histological and immunohistochemical analyses}

Histological evaluation showed that, for all donors, both PD sheets and TKA sheets stained weakly or did not stain for Safranin O or toluidine blue (Fig. 3b, c, i, j). Immunohistochemical analysis showed negative staining for COL2 and positive staining for COL1, FN, and ACAN (Fig. 3d-g, k-n).

\section{Flow cytometric analysis}

PD sheets and TKA sheets showed similar surface markers (Fig. 4). Both PD sheets and TKA sheets were negative for CD31 and CD45 (PD sheets: CD31 $=0.1 \%$, CD45 $=0.1 \%$; TKA sheets: $\mathrm{CD} 31=0.0 \%, \mathrm{CD} 45=0.0 \%$ ). Both PD sheets and TKA sheets were positive for CD44, CD81, and CD90 (PD sheets: CD44 $=99.8 \%$, CD81 $=99.9 \%$, CD90 $=99.8 \%$; TKA sheets: CD44 $=98.7 \%$, CD81 $=98.5 \%$, CD90 $=99.0 \%)$.

\section{Measurement of humoral factors}

The concentrations of humoral factors secreted by PD sheets and TKA sheets are summarized in Fig. 5. PD sheets produced higher concentrations of TGF- $\beta 1$ (PD sheets 1.96 to $3.21 \mathrm{ng} / \mathrm{mL}$; TKA sheets 0.55 to $2.58 \mathrm{ng} / \mathrm{mL}$ ), MIA (PD sheets 9.88 to $35.15 \mathrm{ng} / \mathrm{mL}$; TKA sheets 8.76 to $26.45 \mathrm{ng} / \mathrm{mL}$ ), and TIMP1 (PD sheets 582.60 to $979.60 \mathrm{ng} / \mathrm{mL}$; TKA sheets 83.71 to $798.10 \mathrm{ng} / \mathrm{mL}$ ). TKA sheets produced higher concentrations of MMP3 (PD sheets 5.26 to $22.83 \mathrm{ng} / \mathrm{mL}$; TKA sheets 37.29 to $84.90 \mathrm{ng} / \mathrm{mL}$ ), STC1 (PD sheets 89.00 
Table 1 Theoretical number of chondrocyte sheets that can be fabricated from the collected cartilage tissue

\begin{tabular}{|c|c|c|c|c|c|c|}
\hline & $\begin{array}{l}\text { Wet weight of harvested } \\
\text { cartilage tissue (g) }\end{array}$ & $\begin{array}{l}\text { Cell count after enzymatic } \\
\text { digestion }\left(\times 10^{6}\right)\end{array}$ & $\begin{array}{l}\text { Passage of cells used } \\
\text { to fabricate sheets }\end{array}$ & $\begin{array}{l}\text { Seeding cell density on } \\
\text { temperature-responsive } \\
\text { culture inserts }\end{array}$ & $\begin{array}{l}\text { Number of } \\
\text { layers }\end{array}$ & $\begin{array}{l}\text { Theoretical numbe } \\
\text { of sheets that can } \\
\text { be fabricated }\end{array}$ \\
\hline \multirow[t]{2}{*}{ PD sheets } & $0.3 \pm 0.2$ & $0.17 \pm 0.09$ & 2 & $1 \times 10^{4} \mathrm{cells} / \mathrm{cm}^{2}$ & 1 & 693 \\
\hline & & & 3 & & & 3326 \\
\hline TKA sheets & $9.2 \pm 1.0$ & $18.5 \pm 6.5$ & 0 & $5 \times 10^{4}$ cells $/ \mathrm{cm}^{2}$ & 3 & 29 \\
\hline
\end{tabular}

$P D$ polydactyly-derived chondrocyte, TKA total knee arthroplasty

to $186.60 \mathrm{ng} / \mathrm{mL}$; TKA sheets 153.20 to $626.60 \mathrm{ng} / \mathrm{mL}$ ), and HAPLN1 (PD sheets 30.05 to $33.21 \mathrm{ng} / \mathrm{mL}$; TKA sheets 37.59 to $43.98 \mathrm{ng} / \mathrm{mL}$ ). The concentrations differed significantly between PD sheets and TKA sheets for TGF$\beta 1$, MMP3, and HAPLN1.

\section{Discussion}

The objectives of this study were to characterize sheets fabricated from polydactyly-derived chondrocytes and to compare their properties with those of TKA sheets fabricated from adult chondrocytes. For autologous transplantation, the amount of cartilage tissue that can be collected from nonloading regions is limited, and because of the adult chondrocyte's limited proliferative capacity, coculture with synovial cells to improve proliferation and layering of chondrocyte sheets to increase the secretion of cartilage anabolic factors [24, 26] is necessary. Our results suggest that PDs can proliferate rapidly without coculture. Theoretically, more than 600 PD sheets can be fabricated from P2 cells and more than 3000 PD sheets can be fabricated from P3 cells, whereas the number of autologous chondrocyte sheets that can be fabricated is limited. The possibility of providing a stable supply from a single lot is also attractive for ensuring the quality and safety of chondrocyte sheets.

PD sheets were found to secrete a sufficient amount of extracellular matrix and formed a layered structure during culture without having to be physically layered. This property gives an added advantage during the fabrication process of PD sheets; that is, a single layer of PD sheets, although thinner than layered TKA sheets, displayed enough strength to resist tearing and to be manipulated for transplantation. PD sheets strongly expressed ACAN and FN and were negative for CD31 and CD45, which confirmed that there was no contamination with hematopoietic cells. Similar to TKA sheets, PD sheets also expressed mesenchymal surface markers CD44, CD81, and CD90 and secreted various humoral factors related to cartilage anabolism.

Histological and immunohistochemical analyses revealed that PD sheets and TKA sheets did not stain for Safranin O, toluidine blue, or COL2. However, the autologous chondrocyte sheets that promoted hyaline cartilage repair used in our clinical study also did not stain for Safranin O, toluidine blue, or COL2 (manuscript in
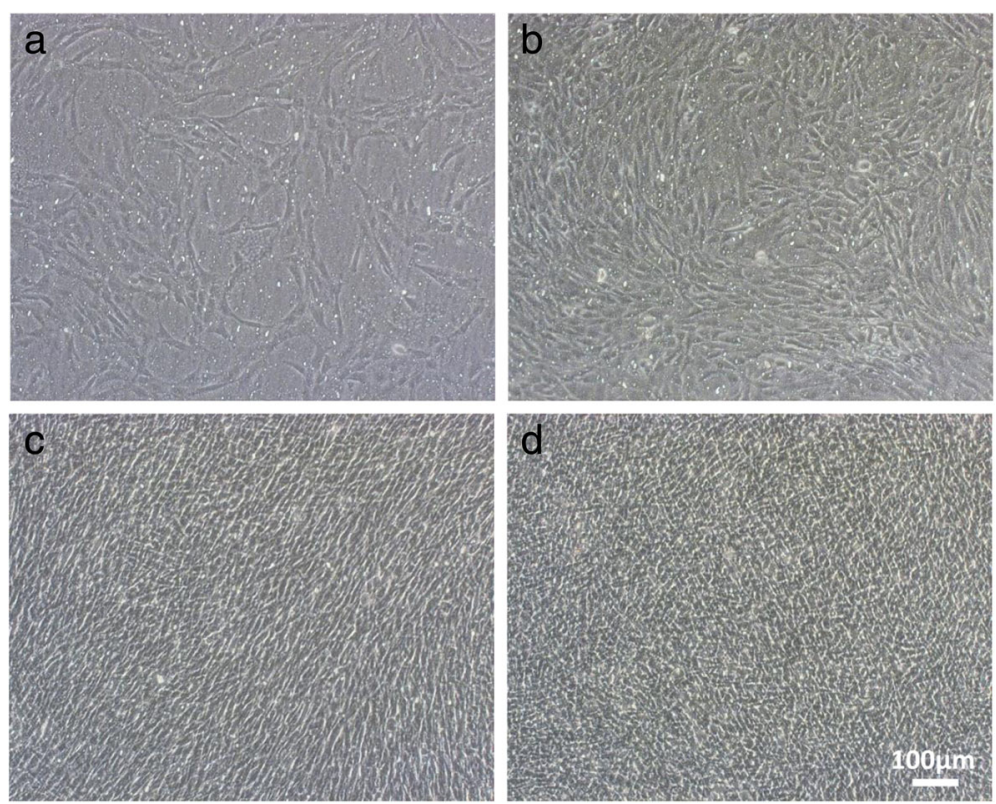

Fig. 2 Microscopic view of the proliferation of PDs. PDs seeded on temperature-responsive culture inserts were observed on day 3 (a), day 5 (b), day 7 (c), and day 14 (d) $(\times 100)$. Cells reached confluence at day 5 and, by day 14, they were tightly packed. (Scale bar $=100 \mu \mathrm{m})$ 

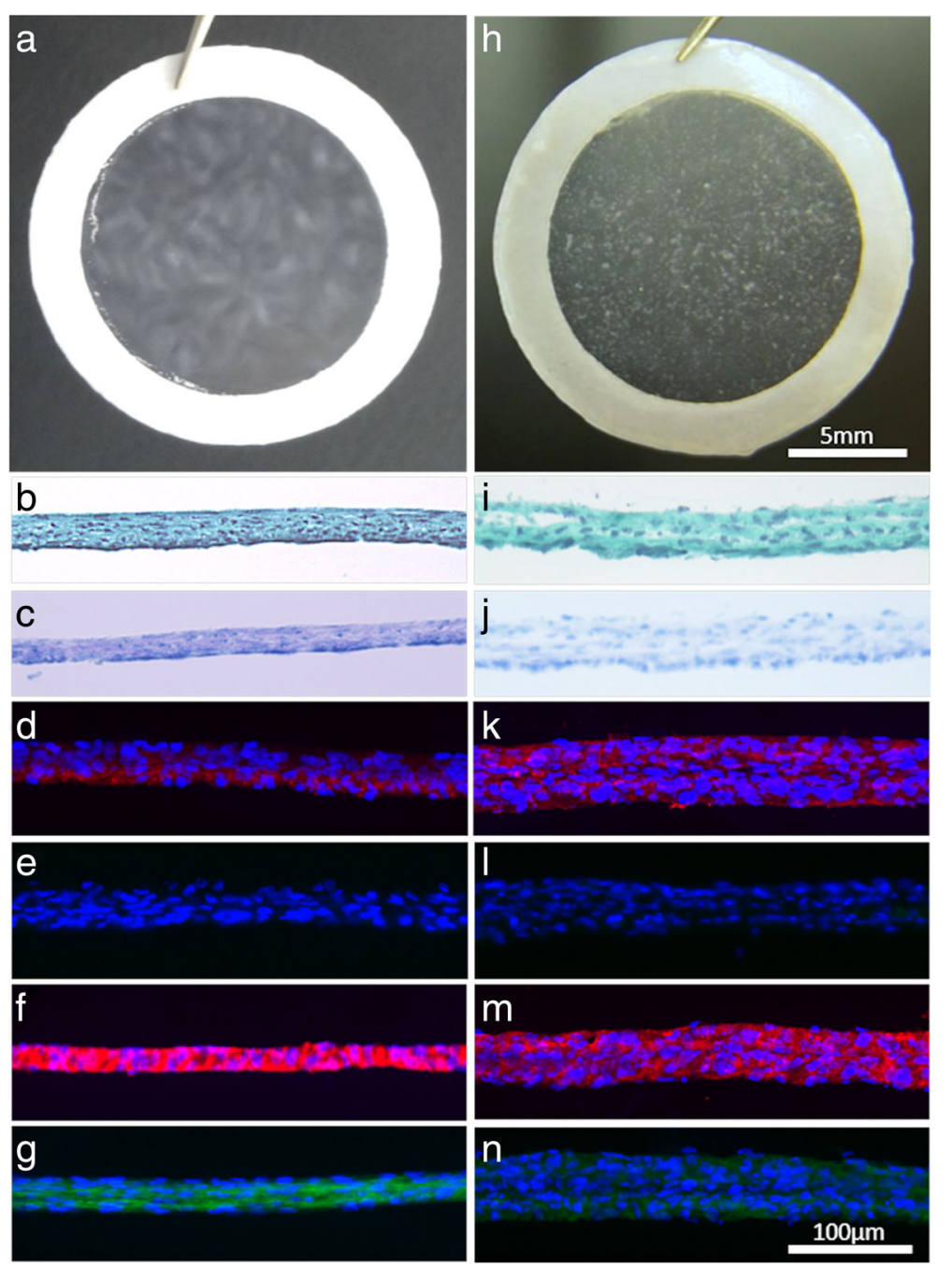

Fig. 3 Macroscopic images and microscopic images of histological sections. Images of PD sheets (a-g) and TKA sheets (h-n). $\mathbf{a}, \mathbf{h}$ Representative images of a PD sheet and TKA sheet attached to a white PVDF membrane. Histological staining for Safranin $\mathrm{O}(\mathbf{b}, \mathbf{i})$ and toluidine blue $(\mathbf{c}, \mathbf{j})$ showed either weak or no staining for all donors ( $\times 20$ ). Immunostaining for COL1 (red; $\mathbf{d}, \mathbf{k})$, COL2 (green; e, I), ACAN (red; f, m), and FN (green; $\mathbf{g}, \mathbf{n})$ showed positive staining for COL1, ACAN, and FN but negative staining for COL2 $(\times 20)$. (Scale bar $=100 \mu \mathrm{m})$

preparation), suggesting that chondrocyte sheets may behave differently in vivo.

The regenerative effects of chondrocyte sheets may be attributed to the protection of cartilage defects from catabolic factors within the synovial fluid, prevention of proteoglycan loss, and continued secretion of cartilage anabolic factors by transplanted chondrocytes that act as initiators of cartilage repair through the recruitment of stem cells from the bone marrow. PD sheets were found to secrete TIMP1, STC1, and HAPLN1, in addition to TGF- $\beta 1$ and MIA as previously reported for TKA sheets [26]. TIMP1 inhibits the catabolic activity of MMP1 and MMP3 [27], and STC1 is involved in the regulation of angiogenesis [28] and inhibition of cartilage hypertrophy and bone formation of growth plate cartilage [29]. HAPLN1 stabilizes the association of ACAN and hyaluronan [30]. Compared with TKA sheets, PD sheets secreted significantly less MMP3, a known catabolic factor [31]. We also detected donor differences in PD sheets for humoral factor concentrations (Fig. 5), indicating that selection of donors based on the secretion levels of humoral factors may be necessary. One limitation of our study was that TKA sheets were fabricated from patients whose ages ranged from 67 to 79 years, and cartilage tissue was collected in bulk from areas that appeared normal. The autologous chondrocyte sheets used in our clinical study were fabricated from patients whose ages ranged from 30 to 59 years, and cartilage tissue was collected from the nonloading regions of knee cartilage. Although TKA sheets were shown to be effective in a rabbit xenogeneic transplantation model (manuscript in preparation), comparisons must be made 


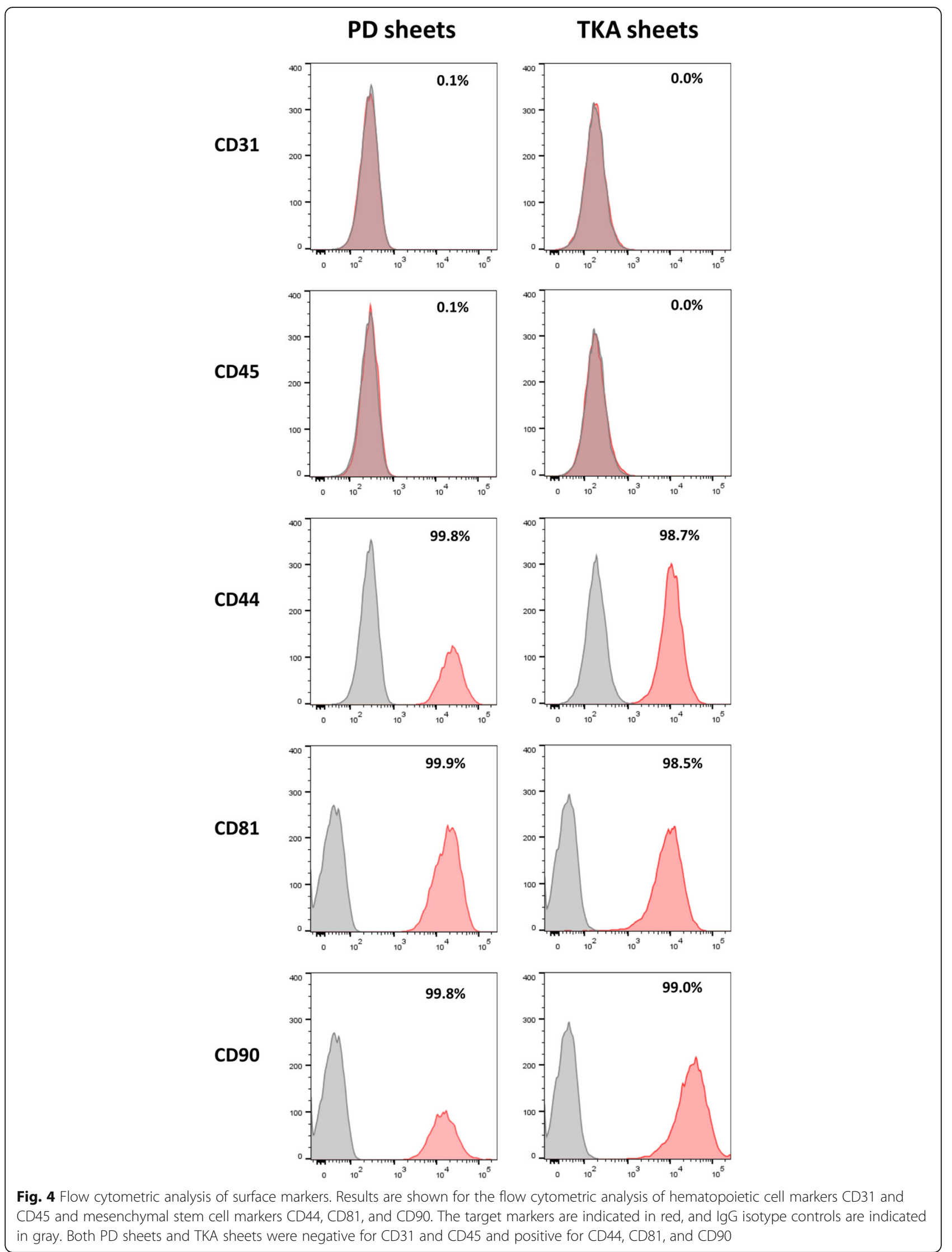




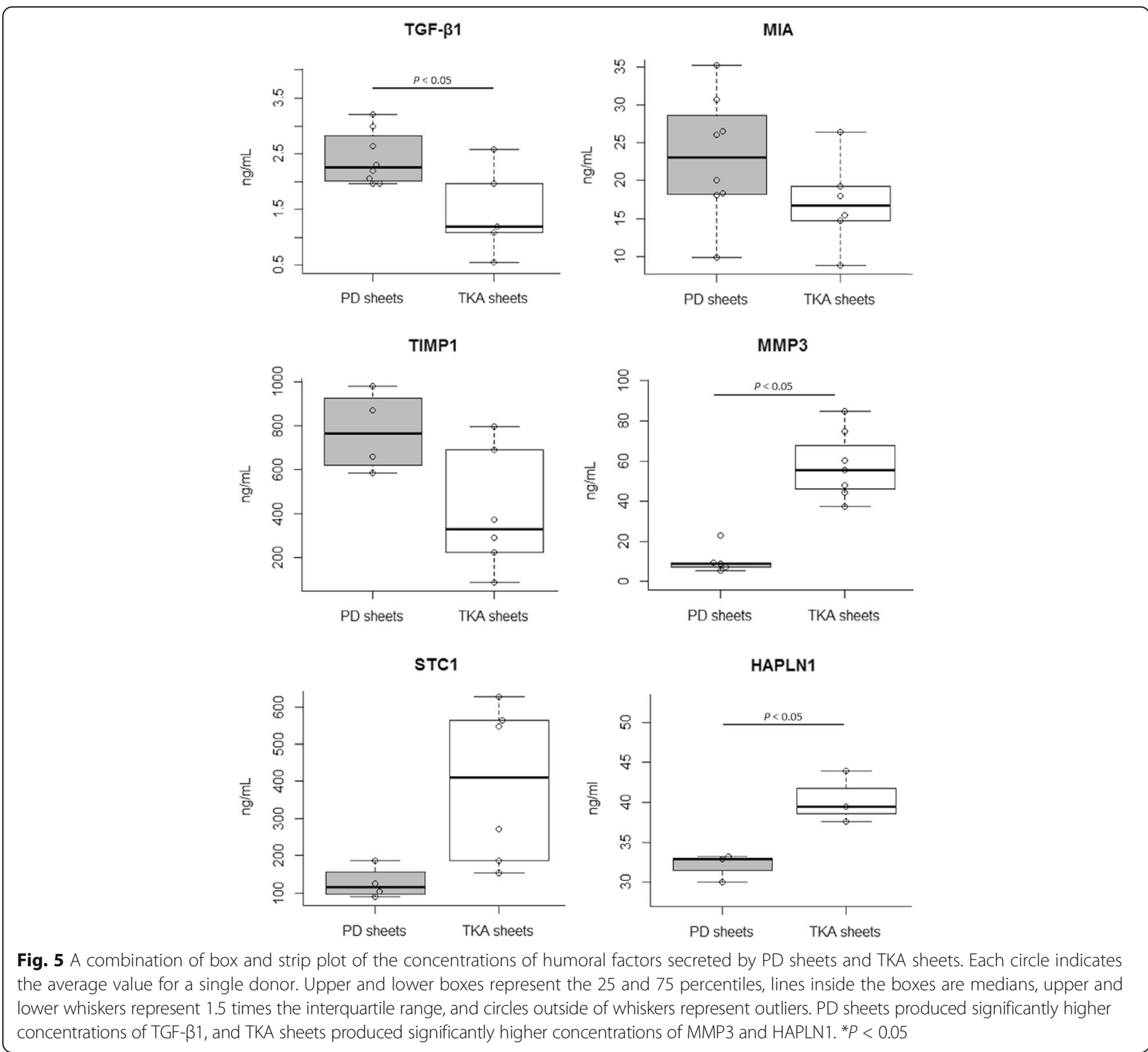

carefully because TKA sheets may be inferior to those sheets used in our clinical study.

Here, we fabricated and evaluated PD sheets from P2 and P3. Current data suggest that the properties of P2 and P3 PD sheets are not significantly different (data not shown). However, the loss of cartilage properties through the passaging of PDs has been reported [32] and must be investigated further. Moreover, the in vivo characteristics of PD sheets are still under investigation. We are currently performing xenogeneic transplantation of human PD sheets into rat and rabbit osteochondral defect models to evaluate their in vivo efficacy. In addition, to make this treatment widely available off the shelf, we are investigating vitrification methods and developing systems for storing PD sheets [33, 34].

We found that PD sheets and adult TKA sheets share important characteristics, and further investigation of their in vivo efficacy will help to provide the evidence necessary to establish PDs as a cell source for allogeneic chondrocyte sheets.

\section{Conclusions}

In this study, we characterized sheets created from PDs and compared key properties with those of TKA sheets. PDs proliferated rapidly to establish a layered structure with sufficient extracellular matrix and formed sheets that could be easily manipulated without tearing. Similar to TKA sheets, PD sheets expressed ACAN and FN at the protein level and produced significantly higher levels of TGF- $\beta 1$ and lower levels of MMP3 than those produced by TKA sheets, suggesting their potential in future clinical applications. 


\section{Abbreviations}

AB: Antibiotic-antimycotic solution; ACAN: Aggrecan; BSA: Bovine serum albumin; CLS1: Collagenase type 1; COL1: Type I collagen; COL2: Type II collagen; DPBS: Dulbecco's phosphate-buffered saline; EDTA: Ethylenediaminetetraacetic acid; ELISA: Enzyme-linked immunosorbent assay; FBS: Fetal bovine serum; FN: Fibronectin; HAPLN1: Hyaluronan and proteoglycan link protein 1; MIA: Melanoma inhibitory activity; MMP3: Matrix metalloproteinase-3; P1: Passage 1; P2: Passage 2; PD: Polydactyly-derived chondrocyte; PVDF: Polyvinylidene difluoride; STC1: Stanniocalcin-1; TGF- $\beta 1$ : Transforming growth factor beta-1; TIMP1: Tissue inhibitor of metalloproteinases; TKA: Total knee arthroplasty

\section{Acknowledgements}

We thank Professor Teruo Okano and Professor Masayuki Yamato (Institute of Advanced Biomedical Engineering and Science, Tokyo Women's Medical University) for expert advice on developing cell sheets.

\section{Funding}

This research was supported by the Research Project for Practical Applications of Regenerative Medicine (No. 12103253 to MS) from the Japan Agency for Medical Research and Development.

\section{Availability of data and materials}

The datasets used and/or analyzed during the current study are available from the corresponding author on reasonable request.

\section{Authors' contributions}

MS, MW, and ET conceived and designed the study. MM performed the cell culture, experiments, and statistical analysis, prepared the tables and figures, and wrote the manuscript. ET and TT wrote the manuscript together with MM. EO and TK performed the cell culture and experiments together with MM. MS and MW supervised the experiments and provided advice for MM. All authors read and approved the final manuscript.

\section{Ethics approval and consent to participate}

All experiments were conducted with the approval of the Tokai University Ethics Committee and with either informed consent from the patient or parental permission.

\section{Consent for publication}

Not applicable.

\section{Competing interests}

MS receives research funding from CellSeed Inc.

\section{Publisher's Note}

Springer Nature remains neutral with regard to jurisdictional claims in published maps and institutional affiliations.

\section{Author details}

${ }^{1}$ Department of Orthopaedic Surgery, Surgical Science, Tokai University School of Medicine, Kanagawa, Japan. ${ }^{2}$ CellSeed Inc., Tokyo, Japan.

Received: 21 August 2017 Accepted: 26 September 2017

Published online: 01 November 2017

\section{References}

1. Paget J. The classics. II. Healing of cartilage. Sir James Paget, Bart, M.D. London, member of the RYAL Society. Clin Orthop Relat Res. 1969;64:7-8.

2. Pridie $\mathrm{KH}$. A method of resurfacing osteoarthritic knee joints. J Bone Joint Surg Br. 1959;41-B:618-9.

3. Steadman JR, Rodkey WG, Rodrigo JJ. Microfracture: surgical technique and rehabilitation to treat chondral defects. Clin Orthop Relat Res. 2001:S362-9.

4. Mithoefer K, Williams RJ, Warren RF, Potter HG, Spock CR, Jones EC, et al. Chondral resurfacing of articular cartilage defects in the knee with the microfracture technique. Surgical technique. J Bone Joint Surg Am. 2006; 88(Suppl 1 Pt 2):294-304.

5. Hangody L, Kárpáti Z. New possibilities in the management of severe circumscribed cartilage damage in the knee. Magy Traumatol Ortop Kezseb Plasztikai Seb. 1994;37:237-43.

6. Szerb I, Hangody L, Duska Z, Kaposi NP. Mosaicplasty: long-term follow-up. Bull NYU Hosp Jt Dis. 2005;63:54-62.
7. Brittberg M, Lindahl A, Nilsson A, Ohlsson C, Isaksson O, Peterson L. Treatment of deep cartilage defects in the knee with autologous chondrocyte transplantation. N Engl J Med. 1994;331:889-95.

8. Roberts S, McCall IW, Darby AJ, Menage J, Evans H, Harrison PE, et al. Autologous chondrocyte implantation for cartilage repair: monitoring its success by magnetic resonance imaging and histology. Arthritis Res Ther. 2003;5:R60-73.

9. Jakobsen RB, Engebretsen L, Slauterbeck JR. An analysis of the quality of cartilage repair studies. J Bone Joint Surg Am. 2005;87:2232-9.

10. Yamato M, Okano T. Cell sheet engineering. Mater Today. 2004;7:42-7.

11. Owaki T, Shimizu T, Yamato M, Okano T. Cell sheet engineering for regenerative medicine: current challenges and strategies. Biotechnol J. 2014:9:904-14.

12. Nishida K, Yamato M, Hayashida Y, Watanabe K, Maeda N, Watanabe H, et al. Functional bioengineered corneal epithelial sheet grafts from corneal stem cells expanded ex vivo on a temperature-responsive cell culture surface. Transplantation. 2004;77:379-85.

13. Ohki T, Yamato M, Murakami D, Takagi R, Yang J, Namiki H, et al. Treatment of oesophageal ulcerations using endoscopic transplantation of tissueengineered autologous oral mucosal epithelial cell sheets in a canine model. Gut. 2007:56:313-4.

14. Shimizu T, Yamato M, Kikuchi A, Okano T. Two-dimensional manipulation of cardiac myocyte sheets utilizing temperature-responsive culture dishes augments the pulsatile amplitude. Tissue Eng. 2001;7:141-51.

15. Iwata T, Washio K, Yoshida T, Ishikawa I, Ando T, Yamato M, et al. Cell sheet engineering and its application for periodontal regeneration. J Tissue Eng Regen Med. 2015;9:343-56.

16. Okano T, Yamada N, Sakai H, Sakurai Y. A novel recovery system for cultured cells using plasma-treated polystyrene dishes grafted with poly $(\mathrm{N}$ isopropylacrylamide). J Biomed Mater Res. 1993;27:1243-51.

17. Okano T, Yamada N, Okuhara M, Sakai H, Sakurai Y, Ota N, et al. Mechanism of cell detachment from temperature-modulated, hydrophilic-hydrophobic polymer surfaces. Biomaterials. 1995;16:297-303.

18. Mitani G, Sato M, Yamato M, Kokubo M, Takagaki T, Ebihara G, et al. Potential utility of cell sheets derived from the anterior cruciate ligament and synovium fabricated in temperature-responsive culture dishes. J Biomed Mater Res A. 2014;102:2927-33.

19. Takaku Y, Murai K, Ukai T, Ito S, Kokubo M, Satoh M, et al. In vivo cell tracking by bioluminescence imaging after transplantation of bioengineered cell sheets to the knee joint. Biomaterials. 2014:35:2199-206.

20. Ito S, Sato M, Yamato M, Mitani G, Kutsuna T, Nagai T, et al. Repair of articular cartilage defect with layered chondrocyte sheets and cultured synovial cells. Biomaterials. 2012;33:5278-86.

21. Ebihara G, Sato M, Yamato M, Mitani G, Kutsuna T, Nagai T, et al. Cartilage repair in transplanted scaffold-free chondrocyte sheets using a minipig model. Biomaterials. 2012;33:3846-51.

22. Kaneshiro N, Sato M, Ishihara M, Mitani G, Sakai H, Mochida J. Bioengineered chondrocyte sheets may be potentially useful for the treatment of partial thickness defects of articular cartilage. Biochem Biophys Res Commun. 2006; 349:723-31

23. Kruse DL, Ng A, Paden M, Stone PA. Arthroscopic De Novo NT ${ }^{\circledR}$ juvenile allograft cartilage implantation in the talus: a case presentation. J Foot Ankle Surg. 2012:51:218-21.

24. Kokubo M, Sato M, Yamato M, Mitani G, Kutsuna T, Ebihara G, et al. Characterization of chondrocyte sheets prepared using a co-culture method with temperature-responsive culture inserts. J Tissue Eng Regen Med. 2016; 10:486-95.

25. Kokubo M, Sato M, Yamato M, Mitani G, Uchiyama Y, Mochida J, et al. Characterization of layered chondrocyte sheets created in a co-culture system with synoviocytes in a hypoxic environment. J Tissue Eng Regen Med. doi:10.1002/term.2192.

26. Hamahashi K, Sato M, Yamato M, Kokubo M, Mitani G, Ito S, et al. Studies of the humoral factors produced by layered chondrocyte sheets. J Tissue Eng Regen Med. 2015:9:24-30.

27. Nagase H, Woessner JF. Matrix metalloproteinases. J Biol Chem. 1999;274: 21491-4.

28. Law AYS, Wong CKC. Stanniocalcin-1 and -2 promote angiogenic sprouting in HUVECs via VEGFNEGFR2 and angiopoietin signaling pathways. Mol Cell Endocrinol. 2013;374:73-81

29. Wu S, Yoshiko Y, De Luca F. Stanniocalcin 1 acts as a paracrine regulator of growth plate chondrogenesis. J Biol Chem. 2006;281:5120-7. 
30. Laurent TC, Laurent UB, Fraser JR. The structure and function of hyaluronan: an overview. Immunol Cell Biol. 1996;74:A1-7.

31. Chen J-J, Huang J-F, Du W-X, Tong P-J. Expression and significance of MMP3 in synovium of knee joint at different stage in osteoarthritis patients. Asian Pac J Trop Med. 2014;7:297-300.

32. Nasu M, Takayama S, Umezawa A. Efficiency of human epiphyseal chondrocytes with differential replication numbers for cellular therapy products. Biomed Res Int. 2016;2016:6437658.

33. Maehara M, Sato M, Watanabe M, Matsunari H, Kokubo M, Kanai T, et al. Development of a novel vitrification method for chondrocyte sheets. BMC Biotechnol. 2013;13:58.

34. Tani $Y$, Sato M, Maehara M, Nagashima H, Yokoyama M, Yokoyama M, et al. The effects of using vitrified chondrocyte sheets on pain alleviation and articular cartilage repair. J Tissue Eng Regen Med. 2017; doi:10.1002/term.2257.

Submit your next manuscript to BioMed Central and we will help you at every step:

- We accept pre-submission inquiries

- Our selector tool helps you to find the most relevant journal

- We provide round the clock customer support

- Convenient online submission

- Thorough peer review

- Inclusion in PubMed and all major indexing services

- Maximum visibility for your research

Submit your manuscript at www.biomedcentral.com/submit
Biomed Central 